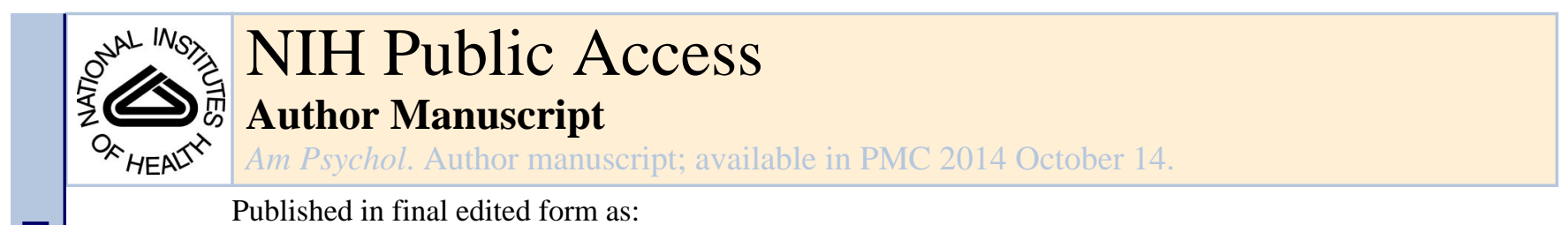

Published in final edited form as:

Am Psychol. 1988 November ; 43(11): 949-957.

\title{
Issues in the Perception of AIDS Risk and Risk Reduction Activities by Black and Hispanic/Latina Women
}

\author{
Vickie M. Mays and \\ University of California, Los Angeles \\ Susan D. Cochran \\ California State University, Northridge
}

\begin{abstract}
Although to date most cases of Acquired Immunodeficiency Syndrome (AIDS) have occurred among men, AIDS poses a serious threat for Black and Latina women, particularly for those who are poor and live in geographic areas of higher AIDS incidence. Yet many may not perceive themselves to be at risk from what has generally been portrayed as a "White gay disease." This article examines patterns of AIDS infection in women and factors associated with risk perception and behavior change. In doing so, the influence of ethnic minority culture on the behavior of individual women is explored.
\end{abstract}

Until recently, most Americans thought of Acquired Immunodeficiency Syndrome (AIDS) as essentially a man's disease afflicting homosexual, bisexual, and intravenous drug abusing males ("Women and AIDS," 1986). However, women have been counted among AIDS cases ever since the deadly disease first emerged six years ago. Of the 66,464 individuals diagnosed with AIDS, reported as of July 4, 1988 to the Centers for Disease Control, 5,757 are women, representing nearly $9 \%$ of all cases (AIDS Weekly Surveillance Report. July 4, 1988). Although this number may seem of relatively small concern when compared with the number of men affected by AIDS, there are important reasons to focus special study on these women.

First, the fact that most cases at present have been diagnosed in men reflects an early epidemiologic pattern of infection by a virus with a long, and still unknown, average latency before disease expression (National Academy of Sciences, Institute of Medicine, 1986). In actuality, the number of cases among women today is approximately equivalent to the number of cases among men only two to three years ago and is expected to reach between 22,000 and 30,000 cases by the year 1991 (Morgan \& Curran, 1986). As can be seen in Table 1, most women with AIDS are of ethnic minority background (Cochran, Mays, \& Roberts, 1988).

Copyright 1988 by the American Psychological Association, Inc.

Correspondence concerning this article should be addressed to Vickie M. Mays, Associate Professor of Psychology, University of California, Los Angeles, 1283 Franz Hall, Los Angeles, CA 90024-1563.

An earlier version of this article was presented at the meeting of the American Psychological Association, New York City, August, 1987. 
Among Latinas, risk is differentially present across the diverse populations that comprise this ethnic group, but the Centers for Disease Control AIDS Public Access Data Tape does not permit making such important distinctions. For example, in 1985 , more than $40 \%$ of AIDS deaths on the Lower East Side of New York City occurred among Puerto Ricans (Worth \& Rodriguez, 1987).

Second, the pattern of infection transmission for women is changing. Whereas in 1982 only $12 \%$ of the women diagnosed with AIDS were presumably infected by their male sexual partners, by $198626 \%$ of women with AIDS were contracting it through heterosexual contact (Guinan \& Hardy, 1987). Of these women infected through sexual activity, 77\% are Black or Latina. Estimates (reported in "Bleak Lives," 1987) are that up to 50,000 women in New York City are human immunodeficiency virus (HIV) seropositive. For women in New York City, the prevalence of infection is thought to be $50 \%$ among intravenous (IV) drug users and $20 \%$ among those whose sexual partners are IV drug users. Of these women, $80 \%$, or 40,000, are most likely Black or Latina. Since 1980, AIDS has become the sixth leading cause of years of potential life lost before age 65 for women in New York City, and for those between the ages of 25 and 29, AIDS is the most frequent cause of death (Kristal, 1986). Experts estimate that heterosexual transmission will increase sevenfold in the next five years (Villarosa \& Roberts, 1987). Nationwide, it is thought that approximately 100,000 women are HIV-infected ("Bleak Lives," 1987).

A third reason to be concerned about AIDS in women is that most pediatric cases of AIDS in the past have and virtually all in the future will result from infection acquired from an HIV-positive mother (Brooks-Gunn, Boyer \& Hein, this issue, pp. 958-964). Further reductions in the incidence of pediatric AIDS are dependent upon the choices and behavior of infected women, many of whom are unaware of their infection status.

Finally, AIDS, as a behaviorally transmitted disease, often through sexual contact, involves the behavior of both men and women. Risk reduction relies on altering the intimate behaviors of individuals during sexual activity. In this context, it seems relevant to explore women's sexual and contraceptive behavior. Because AIDS risk reduction activities are sometimes identical to contraception efforts (e.g., using condoms), it is reasonable to extrapolate what is known about women and contraceptive behaviors in anticipating potential issues with encouraging "safer" sexual practices aimed at reducing AIDS transmission.

In focusing on AIDS and women, our primary concern is with poor, urban, ethnic women because, at present, this is one of the populations most at risk for acquiring an HIV infection. This look at issues surrounding perceptions of risk and risk reduction activities by Black and Latina women may prove valuable in attempts to stop the spread and transmission of the disease. In doing so, it will also become quickly apparent that the AIDS epidemic has highlighted both the good and bad aspects of our society, particularly as it relates to ethnic minorities. 


\section{Ethnic Women and Sexual Risk Reduction}

AIDS is playing a major role in the growing concern about all sexually transmitted diseases (Cochran \& Keidan, 1988; Cochran \& Peplau, 1988). Consumer studies, for example, indicate that in 1987 American women purchased approximately $40 \%$ of the condoms sold, an increase of $15 \%$ since the discovery of AIDS (Battle, 1986). Even popular magazines provide detailed advice on how to avoid an HIV infection through changes in sexual conduct (e.g., "What You Must Know," 1987).

This picture, though, may not be consistent with the behaviors of ethnic women, particularly those who are poor or less behaviorally directed by Euro-American culture. In a study of 233 adolescent Latinas experiencing their first birth, approximately $20 \%$ did not know that condoms are an effective birth control device (Erickson \& Scrimshaw, 1986). Additionally, $28 \%$ failed to recognize spermicides as a method of birth control. A second study (Marin \& Marin, 1987) demonstrated that many Hispanics are unaware that spermicides containing nonoxynol-9 may be effective in inactivating HIV and thus possibly reducing risk of infection.

Black adolescents are also relatively uninformed about contraceptives and use birth control methods poorly (Clark, Zabin, \& Hardy, 1984; Flora \& Thorensen, this issue, pp. 965-970; Gibbs, 1986). In a recent study of 98 sexually active Black women college students (Mays \& Cochran, 1988a), only $50 \%$ used birth control on a regular basis; $36.5 \%$ did not use birth control at all. If we focus specifically on the use of condoms, $17 \%$ had never used them and $48 \%$ employed them only rarely. More than half had brought up the topic of condoms with their sexual partners fewer than three times. Finally, less than a quarter insisted on using condoms during sex as a means of reducing their risks for sexually transmitted disease such as AIDS, despite the fact that $94 \%$ of respondents knew that condoms were effective in reducing risks associated with AIDS. This demonstrates that knowledge alone of AIDSrelated risks does not necessarily translate into AIDS risk reduction behaviors, a fact wellknown from historical efforts to combat sexually transmitted diseases (Brandt, 1988).

This low rate of employing condoms for contraceptive or health reasons reflects a historical change in the extent to which women have taken over control of contraception. Wyatt, Peters, and Guthrie (1988) compared condom use in their sample of Black women between the ages of 18 and 36 years recruited in 1986 with a comparable age group from Kinsey's 1953 sample. Results showed that $80 \%$ of the Kinsey sample partners used condoms whereas only $46 \%$ in the later (Wyatt et al., 1988) sample used condoms. They reported that Black women today tend not to use methods of birth control that depend on their partners' behavior (e.g., withdrawal before ejaculation or condoms). Yet, advice on prevention of AIDS asks women to return to reliance on men's behavior to protect them from the consequences of sexual involvement. (For a fuller discussion of this issue see Cochran \& Mays, in press). We must not underestimate the variety of ethnic, racial, cultural, and religious factors that influence sexual behavior patterns. For some ethnic women the behavior change of using condoms must be viewed as more important than their religious doctrines. To make such a profound change in sexual behavior, ethnic women must begin to perceive themselves to be at risk for AIDS. 


\section{Perceiving AIDS Risk}

Despite the increasing attention focused on AIDS, ethnic women may not consider their own personal risks to be high for several reasons. Most women, particularly when their life reality is that of being poor, Black, Latina, or outside the law through drug abuse or street prostitution, have always lived with risks of some kind. AIDS is simply one more risk with which to be concerned. These women have long histories of facing omnipresent dangers not often experienced by the middle class and mustering what scarce resources exist to cope with these dangers (Mason, Ogden, Berreth, \& Martin, 1986). The key to poor ethnic women's response to AIDS is their perception of its danger relative to the hierarchy of other risks present in their lives and the existence of resources available to act differently. Competition for these women's attention includes more immediate survival needs, such as obtaining shelter for the night, securing personal safety or safety of their children, or interfacing with the governmental system in order to obtain financial resources. For women who often, realistically, feel powerless to change the external realities of their lives-where they live, how much they earn, or the system's rules for getting financial supplementsAIDS may be of relatively low concern. In addition, even if AIDS is perceived as a relevant danger, women may not readily have the means to reduce their risk.

There are other reasons why women most at risk for acquiring an HIV infection are less worried than they might be. In appraising risk, they are influenced, as we all are, by credible sources, and this perceived risk determines actions (Weinstein, 1987). In the study of Black college students described earlier (Mays \& Cochran, 1988a), almost $50 \%$ of sexually active Black women worried very little or not at all about getting AIDS. Furthermore, approximately $30 \%$ had done nothing to reduce their chances of getting a sexually transmitted disease. Most distressing was that, contrary to actual fact, they viewed Blacks as significantly less likely than Whites to get AIDS. Sampling for this study was done in Southern California, an epicenter for AIDS education activities. These young women were not poverty-stricken, uneducated, or even unexposed to AIDS information, yet like many other Black and Latina women, they believed AIDS to be a White problem.

The influence of the mass media on the beliefs of the public is a known fact of consumer advertising (Warner, 1987; Williams, 1986). The role of the media in health education is based on several theories of communication aligned with theoretical constructs from social psychology (Williams, 1986; Winett, 1986). With the exception of individuals involved in AIDS activities, most members of ethnic minority communities learn about AIDS via the print media and, most frequently, from television. However, usually when someone of authority on the screen talks about the risks of AIDS, this individual is a White male, not an ethnic minority member, and seldom an ethnic woman. The effectiveness of health messages in altering attitudes and subsequent behavior is influenced in part by the credibility of the individual who delivers the message. It is possible that if the Black women college students described previously were contemplating sex with a White male or a man who appeared gay, they might worry about AIDS. Otherwise, this disease, given everything else to worry about, may seem irrelevant. For the poor ethnic woman, the prostitute, or the female drug abuser, denial and underestimation of personal vulnerability may be considerably easier than undertaking significant behavior changes that accompany a major change in life-style. 


\section{Risk Reduction in Context}

The incidence of AIDS infection among Black and Latina women will continue if risk reduction education is not presented in its appropriate context - that of an interpersonal decision-making framework. Behaviors that we, as concerned psychologists, aim to change in these women are often linked to (a) personal identities, (b) psychological issues, (c) social networks that function as important sources of emotional and tangible support, or (d) social, ethnic, or cultural norms. It is important to remember these links when we ask women to just say no to sex or to sharing of drug injection equipment and to insist on condom usage. Like all behavior, AIDS risk-related behavior is tied to other facets of people's lives, and change in one realm can affect others (Winett, 1986). This notion of interdependency is particularly important to keep in mind when attempting to change health behaviors that are often intermeshed (Winett, 1986).

Behaviors most directly related to HIV transmission are interpersonal in nature, involving intimate human interactions often prescripted by sex role norms, gender, economics, and culture. Changes in these behaviors therefore require changes in the nature of interpersonal relationships among individuals within higher risk groups (Des Jarlais, Tross, \& Friedman, 1987). Obviously, our interventions need to be tailored to the cultural realities of the particular group in question.

\section{Drug-Related HIV Transmission}

Rates of intravenous drug abuse are high in poor ethnic minority communities (Gary \& Berry, 1985), accounting for some of the overrepresentation of ethnic minorities among IV drug abuse-related AIDS cases (Cochran et al., 1988; Mays \& Cochran, 1987). Drug dealing in poor ethnic minority communities can provide an important economic base for women and their families (Mays \& Cochran, 1988b; Worth \& Rodriguez, 1987).

For the drug-addicted woman, motivation for a lifestyle change (i.e., drug abstinence and the need to change one's social network) may require a change in perceived self-efficacy, selfesteem, perceived peer group norms, or beliefs about the controllability of the future. Exploring with a drug-addicted woman her ability to negotiate safer sex behaviors or safer drug paraphernalia use involves facing psychosocial issues of powerlessness, sociocultural pressures associated with poverty (Nelson \& Mandanaro, 1981; Worth \& Rodriguez, 1987), or emotional needs for intimacy or for an intimate relationship. For example, it is not uncommon for an intravenous drug addict to allow a "buddy" to share a "wash," a useful means of delaying withdrawal symptoms until more drugs can be found. In this procedure, the friend fills a recently used, and therefore potentially HIV infected, syringe with water and injects the solution. This is an instance of friendship and loyalty, not an isolated, impersonal act.

The reality is that IV drug use is not a simple autonomous behavior, but rather a pattern of behaviors often deeply embedded within a subculture that has its own values, roles, and status allocations. This subculture, like any social system, provides its members with both emotional and tangible support (Friedman, Des Jarlais, \& Sothern, 1986). Reflecting this, 
risk reduction activities on the part of Black addicts in New York City were best predicted by whether or not their buddies were engaging in such activities (Des Jarlais et al., 1987).

\section{Sexually Related HIV Transmission}

AIDS sexual risk reduction is a behaviorally driven action and as such must be treated within an interpersonal context (Cochran \& Mays, in press). For example, some risk reduction messages advise the general public to consider sexual abstinence (Koop, 1986). Yet, for poor women, sex may function as a source of employment, a method for establishing ownership or proprietary rights in a relationship, or as a means of acquiring much needed tangible or emotional support. Under these circumstances, abstinence is not a realistic option. For the prostitute, in particular, sex is money, and unsafe sex is often more money. In our risk reduction advice, we have not offered the sex industry worker an economic substitute should she choose abstinence. For her, safer sex may already be an economic compromise.

When abstinence is not possible, the Surgeon General advocates the use of condoms. Yet little attention has been given to the context of condom usage for Black and Latina women. A small subset of Black and Latina women experience physical and verbal abuse in response to requests for their partners to use condoms. Although the sexual behavior of these cultures, particularly Blacks, has received some attention and generated many myths, little factual information is available (Wyatt, in press).

For traditional Hispanic or Latina women in particular, cultural pressures toward female naiveté and sex only within the context of marriage (Burgos \& Perez, 1986; Pavich, 1986) may stigmatize women who take AIDS preventive actions (such as supplying their partners with condoms) as "loose" women (Mantell, Schinke, \& Akabas, in press). Although AIDS risk reduction messages advocate female initiation of condom usage, among some traditional Latin cultures authorization for use of contraceptives lies with the husband (Poma, 1987). It is estimated that approximately $25 \%$ of Latino husbands oppose any form of birth control (Poma, 1987).

Similarly, public health messages requesting women to discuss sexual practices and condom usage with their sexual partners do so in ignorance of cultural norms governing sexual behavior. As noted above, traditional Hispanic women are expected to be modest, faithful, and virginal. Cultural norms dictate that these women enter marriage with little knowledge about sexual practices and rely on their husbands for the acquisition of this knowledge. It is also not generally normative to discuss sexual matters (Worth \& Rodriguez, 1987). Current messages advocating knowledge of the sexual history of one's partner and discussing "safer sex" before sexual involvement ignore these normative expectations for women's behavior. Behavior inconsistent with these norms may be viewed negatively by a woman's partner and adversely impact a developing relationship.

Suggestions to use condoms also overlook the reality that some Black women, unfortunately those at higher risk for AIDS, have yet to incorporate effective birth control methods into their sexual behavior repertoires in the first place. For example, a study of heroin-addicted women, many of whom were in their childbearing years, found that they often did not 
practice birth control because of experiencing high rates of addiction-related amenorrhea (Ralph \& Spigner, 1986). The women assumed incorrectly that they were infertile, but in reality there was simply decreased fertility. When they did use birth control, these same women were more likely than a comparative national sample (drawn from the 1982 National Survey of Family Growth) to rely on the pill as a contraceptive method and were less likely to use condoms ( $3 \%$ vs. $11 \%$ ).

Another concern for women is that the use of a condom is most difficult with one's most intimate partner (Mantell et al., in press). Research on prostitutes suggests that HIV infections were transmitted primarily, not from their sex work activities, but in sexual encounters with their boyfriends or through intravenous drug use (Mantell et al., in press). A poor ethnic woman in a relationship with a male partner, regardless of whether he is an intravenous drug user or not, has the prestige of not being single, but of being married, involved, or "kept." This status is more difficult to achieve in the Black community because the sex-ratio imbalance (percentage of single adult men to percentage of single adult women) is more prominent for Black women than for White women. Nationally, there are 75 unmarried Black men over the age of 15 for each 100 similar status Black women, whereas among Whites this ratio is 81 to 100 (U.S. Bureau of the Census, 1983). The scarcity of eligible men polarizes the status of being single versus not single and puts even more pressure on some Black women to give in to sexual pressures from men for unsafe sex.

\section{Perinatally Related HIV Transmission}

It has been suggested that HIV-positive women choose abortions if pregnant. But for poor ethnic women, this advice may be particularly problematic. In 1983, Black women were nearly 2.25 times more likely than White women to have prenatal care only in the third trimester or to have no prenatal care at all (U.S. Department of Health and Human Services, 1986). Many times the pregnancy was not planned. Recommendations for abortions not only are out of the question due to the lateness of the pregnancy before contact with health care professionals, but for some women abortion may be in conflict with the wishes of the woman's partner, her cultural norms, or her religious beliefs. In the midst of our AIDS risk reduction messages regarding pregnancy, we have also failed to be sensitive to the special value of children for Black and Latina women. Much psychological research has centered on parents' socioemotional and individualistic reasons for bearing and nurturing children (Day $\&$ Mackey, 1988). Yet, from a more anthropological perspective, cultures profoundly influence individuals' attitudes and behaviors related to fertility and abortion. For ethnic minorities, outnumbered by the majority culture, children represent potential cultural survival of the group. In this respect, during the early 1970s, Blacks viewed the use of contraceptives as a form of ethnic genocide promulgated by Whites. The ability to reproduce was seen as a powerful tool in the fight for liberation. Children serve a variety of cultural utilities and may increase the economic resources of a family unit (Day \& Mackey, 1988). Our AIDS risk reduction efforts will be hindered to the extent that we misinterpret Black and Latina women's childbearing and abortion decisions. Acknowledging the sociocultural dynamics of the behavior will allow for better counseling in AIDS risk reduction activities. We cannot simply ask women not to do something merely because we perceive it as risky without some replacement to satisfy the original goal of the risky behavior. 
Asking an HIV-positive intravenous drug abuser to forego having children ignores the reality that the "teachable moment" of pregnancy is sometimes a serendipitous motivator for becoming and staying drug abstinent. The birth of a child may also serve as a social bond to a continuing relationship with a Black male who, because of the scarcity of men, is a precious commodity. In White families, the birth of a child may symbolize continuance of a family legacy; in the poor Black family, the birth of each child signals the possibility for a legacy to begin. This may be especially true for those parents whose only hope may be to leave a child in the world who will go on to accomplish all the things that they and their family of origin never had the opportunity to achieve.

\section{Encouraging Risk Reduction}

AIDS risk reduction advice asks women to change their behavior as if the behaviors do not have a social context. Yet no substitute is offered. Women are merely told "don't" because to do is risky. Efforts at encouraging risk reduction in the ethnic minority communities need both to tailor public health advice appropriately and to use existing positive normative influences.

\section{Structuring the Message}

Behavioral scientists have known for some time that people are more likely to engage in a target behavior if the information is not presented in an overly fear-arousing manner. Rather it is important to present individuals with concrete steps that can be taken on their own behalf (Solomon \& DeLong, 1986). This lessens the likelihood of engaging in denial, adopting a fatalistic attitude, or dismissing the information. The lesson was well learned in the educational campaigns directed at gay men. Many of these interventions, rather than insisting on abstinence, promoted lower risk ("safer") sex and emphasized new, substitute activities. Such advice was consistent with the cultural norms and politics developed within the gay liberation movement that had fought for unrestricted sexual experiences as an expression of positive gay male identity and community.

These same principles of specifically tailoring advice to the cultural and political realities of the target community are essential for risk reduction interventions aimed at Black and Latina women. Yet ethnic women are asked to engage in safer sex when they may not know or understand what safer sex is because the preventive messages have been much too complicated. For instance, women are asked to "negotiate" safer sex contracts in relationship situations when some may not understand the word negotiate. But ethnic women do understand male-female relationships within their own communities. Despite risk reduction advice to "talk to their prospective partners," a rather middle-class notion, poor women may not bother to ask men about previous sexual or drug use behaviors because they know the men will lie or discount the risk.

Women are advised to have one lifelong sexual partner, although they live in a community with a high sex-ratio imbalance and instability of relationships. Should a woman fail at her latest relationship, is she to conclude that another involvement this year would mean that she has had multiple partners? What guidance have we provided as to what constitutes multiple partners? Some women interpret this to mean several partners during one sexual encounter, 
whereas others understand it as having several boyfriends at the same time. Messages that advocate monogamy, when $65 \%$ of Black women and $47 \%$ of Latina women over age 15 are not currently married (versus $43 \%$ of White women), ignore the social and contextual reality of their lives.

Developers of risk reduction messages may be taking a friendship-like model of love relationships, a model based more on power equality, and imposing it as the foundation for their advice. In friendship-based love relationships, honesty and disclosure are valued. However, there are other models of relationships, ones where past sexual behaviors or relationships are expected to be kept secret until the relationship has been well established.

It is wise to remember that poor people do not always have the luxury of honesty, which is much easier when there is sufficient money and resources to guide one's choices. When a poor ethnic woman meets a man of unknown background whose current presentation appears to be that of a clean-cut, upwardly mobile man, she does not ask questions. A prior jail term, so much more common for ethnic men, as opposed to White men, may have involved same-sex consensual activities or rape. Or there may have been drug addiction in a man's past because drug addiction is a widespread problem in the poor ethnic community. Equally possible is that a woman may conceal her own background. In a New York Times article ("Bleak Lives," 1987), one drug-addicted woman acknowledged that although she had her partners use condoms and practiced safer sex, she had not told her current boyfriend that she had AIDS. Cognizant that this omission might cost her the relationship, her hope was that the relationship would be strong enough to continue once he became aware of her illness. Having lost an earlier prospective boyfriend after disclosing her illness, she had learned to conceal this information because in her own words she "can barely imagine life without a man." For some ethnic women, the risk of being alone and unsuccessful in relationships may seem greater than the risk of having or transmitting AIDS.

However, there are other ways of structuring AIDS-prevention messages that may prove more effective. This involves incorporating two dimensions into current activities. First, in targeting risk behaviors for change, it is important that the origins of those behaviors be understood from both an individual and sociocultural perspective. What is the role of community norms? How will behavior change affect economic or emotional support within relationship or family units?

Second, prevention approaches need to focus comprehensively on the individual as a responsible member of a social or familial network. For Black Americans, as an example, ethnically based values of cooperation and unity may be more powerful motivators of behavior change than strict appeals to individualistic action, such as "protect yourself." Successful civil rights activists, such as Martin Luther King, Jr., mobilized the Black community by calls for unity and faith in a vision for collective freedom. Kwanzaa, an indigenous Afro-American holiday, celebrates the community's core values of unity, selfdetermination (ethnic rather than individual), collective work and responsibility, cooperative economics, purpose, creativity, and faith. 
All of these values can readily be incorporated into AIDS risk-reduction messages. For example, one model of AIDS education that appears effective in changing attitudes and behaviors in some segments of the Black community is an appeal for change based on responsibility to others in the community. Men are asked to practice safer sex in order to survive as a needed father or support for their parents. Women are asked to be more assertive regarding condom use in order to stay alive to take care of their parents and children. Possibly men and women could be encouraged to practice risk reduction in order to ensure the existence of the Black race and to build a future for others. This approach is based on a model of social responsibility rather than individualistic preservation.

\section{Involving the Community}

Ethnic communities, and the normative pressures that they can bring to bear on individuals' sexual and drug-related behaviors, differ from the majority culture in subtle but important ways. Some of these differences may be seen initially as problematic. For example, conservative religious beliefs and important church affiliations, more common for Black and Latina women, can be viewed by AIDS educators as impediments to AIDS-related education and risk reduction activities. This is because some risk reduction messages clash with the theology of the particular denominations in which Blacks and Latinos often hold membership. An often used AIDS risk reduction message is that of "Play it safe." The assumption here is that sex is play, fun, or a leisure activity. However, within a fundamentalist religion, sex is viewed as behavior sanctioned by God for procreation. Religious beliefs that reject the use of condoms on the grounds that the purpose of sex is procreation and not recreation may frustrate some AIDS educators.

To some extent though, this frustration may stem from an overdependency on using churches as the major site for programs and a failure to plan multilevel interventions. Yet seldom in targeting public health hazards has there been a reliance on one locale for the delivery of the message. Those churchgoers who cannot within the context of churchsponsored AIDS education learn about condoms should, nonetheless, be able to receive this information from their local pharmacist (Mays, in press), through television and radio public service announcements, or from community outreach workers in, for example, the local beauty shop. It is important to work within the natural context of the community (Rappaport, 1977).

In that respect, churches can provide needed supports for both those who are attempting to reduce their risk of getting AIDS and others who are directly affected by the HIV epidemic, including caretakers, orphaned children, and the sick. Among terminal illnesses, AIDS is a particularly treacherous and stressful one. The emotional and tangible resources of the community of churchgoers may assume increasing importance as the epidemic spreads in ethnic minority communities.

A second issue that may impede the involvement of the ethnic communities is the perception that AIDS is being imposed on the community by the White majority culture. For Blacks, there is sometimes the perception that the community has enough problems without adding AIDS to the list. For both Latinos and Blacks, homosexuality as a self-imposed identity is somewhat culturally foreign (Carrier, 1985; Cochran \& Mays, 1988; Cochran et al., 1988; 
Mays \& Cochran, 1987), and so there is a tendency to underestimate the extent of the behavior within the community. When AIDS educators seek to provide services to the ethnic communities, natural tendencies to export relatively directly effective risk reduction strategies from the White gay men's community must be seriously questioned (Cochran \& Mays, 1988) because it is certain that the community will question these approaches. However, the resistance may be misunderstood by Whites because of cultural differences that influence the articulation of why the program is inappropriate.

\section{Recommendations}

It is necessary that public health officials interpret the risk of AIDS to women in a manner that is understandable, relevant, and effective. AIDS information must be placed within a context that locates the risk of AIDS relative to other risks in women's lives.

The delivery of AIDS messages may best be accomplished by individuals with whom women can identify. Although poor and ethnic women view health care professionals as credible sources, they may dismiss, not the facts of their message, but the personal relevance. Health care professionals have long been associated with other risk messages (e.g., smoking, obesity, cardiovascular diseases) that carry warnings of death. Results from smoking cessation research (Levanthal \& Cleary, 1980) provide some evidence for the effectiveness of messages when they are delivered by a credible source, targeted at a specific audience, and combined with community and peer support. Although AIDS-risk behaviors differ, the same principles appear to be effective in campaigns aimed at gay men. For drug addicts, the effective message carriers appear to be other addicts or ex-addicts; for prostitutes, it may be other prostitutes or sex industry workers ("Street Outreach Workers," 1987).

It is difficult for women to change behavior when they do not personally perceive it to be risky. Psychologists, as skilled researchers in the study of human behavior, need to focus research endeavors on understanding the development of personal perceptions of risk, particularly in the area of health threats and behavior change.

For those women who do perceive their personal risk of AIDS, the important intervention may be to assist them in translating this knowledge and awareness into appropriate behavior. Community psychology has developed a significant foundation for the design of community-based interventions that assist individuals in the modification or change of behavior within their own cultural milieu (Rappaport, 1977). This body of applied research could better guide public health officials in the design of community level AIDS interventions. This seems particularly salient in the face of preliminary data that suggest that changing of AIDS risk-related behaviors seems best predicted by community group norms (Des Jarlais et al., 1987).

In order to reduce risk, women may require assistance in translating knowledge about HIV transmission and the need for safer sex into successful verbal and behavioral repertoires (Tross, 1987). Efforts to achieve this must be sensitive to the special issues for women from ethnic and lower socioeconomic strata. For some women the emphasis may lie more with nonverbal than verbal skills. For example, some workers in the sex industry who are 
commonly faced with clients who reject the use of condoms have developed the ability to put on a condom without the customer's knowledge (Alexander, 1987). Another example in which explicit sexual conversation is avoided is through a risk reduction packet that a potential date receives. The package, "A Close Encounter of a Safer Kind," contains a condom, lubricant, pictured directions on the proper use of a condom, and an invitation to be filled in indicating time, date, and place of the date. This risk reduction packet was developed for distribution in a predominantly Black district (Spectrum, 1987).

Psychologists, particularly community psychologists, have a long and successful history in designing interventions that help individuals modify behavior within a context incorporating sociocultural dimensions. It is this expertise that psychology can add to the current public health AIDS prevention programs. As a profession, psychology has much to offer in the fight against AIDS.

\section{Acknowledgments}

This article represents an equal collaboration between the two authors; order of authorship was randomly determined. The authors would like to thank Pamela Reid, Gail Wyatt, Susan Scrimshaw, and Milagros Davila for their comments on an earlier draft. Preparation of this article was supported in part by the National Institute of Mental Health (Contract No. 87M0198343, Grant No. R01 MH 42584-01), a Biomedical Research Support Grant from the University of California, Los Angeles, and a National Research Services Award (T32 HS 00007) from the National Center for Health Services Research and Health Care Technology Assessment to the first author, and a California State University, North-ridge Foundation grant to the second author.

\section{REFERENCES}

Acquired Immunodeficiency Syndrome (AIDS) Weekly Surveillance Report, United States AIDS Activity. Atlanta, GA: Centers for Disease Control, Center for Infectious Disease; 1988 Jul 4.

Alexander, P. Prostitutes are being scapegoated for heterosexual AIDS. In: Delacoste, F.; Alexander, P., editors. Sex work: Writings by women in the sex industry. Pittsburgh: Cleis Press; 1987. p. 248-263.

Battle CU. Women and AIDS. Journal of the American Medical Women's Association. 1986; 41:2. $37,61$.

Bleak lives: Women carrying AIDS. New York Times. Aug 27.1987 15.

Brandt AM. AIDS in historical perspective: Four lessons from the history of sexually transmitted diseases. American Journal of Public Health. 1988; 78:367-371. [PubMed: 3279834]

Brooks-Gunn J, Boyer CB, Hein K. Preventing HIV infection and AIDS in children and adolescents: Behavioral research and intervention strategies. American Psychologist. 1988; 43:958-964. [PubMed: 3214008]

Burgos NM, Perez YID. An exploration of human sexuality in Puerto Rican culture. Journal of Social Work and Human Sexuality. 1986; 4:135-150.

Carrier, JM. Mexican male bisexuality. In: Klein, F.; Wolf, T., editors. Bisexualities: Theory and research. New York: Haworth Press; 1985. p. 75-85.

Clark S, Zabin L, Hardy J. Sex contraception and parenthood: Experiences and attitudes among urban Black young men. Family Planning Perspectives. 1984; 16:77-82. [PubMed: 6723943]

Cochran S, D'Keidan J, Kacechstein A. Changes in AIDS-related concerns and sexual behavior among young adults. 1988 Manuscript submitted for publication.

Cochran, SD.; Mays, VM. Epidemiologic and sociocultural factors in the transmission of HIV infection in Black gay and bisexual men. In: Shernoff, M., editor. A sourcebook of gay/lesbian health care. 2nd ed.. Washington, DC: National Gay and Lesbian Health Foundation; 1988.

Cochran SD\&, Mays VM. Women and AIDS-related concerns: Roles for psychologists in helping the worried well. American Psychologist. in press. 
Cochran, SD.; Mays, VM.; Roberts, V. Ethnic minorities and AIDS. In: Lewis, A., editor. Nursing care of the patient with AIDS/ ARC. Rockville, MD: Aspen; 1988. p. 17-24.

Cochran SD, Peplau LA. Sexual risk reduction among young heterosexual adults. 1988 Manuscript submitted for publication.

Day RD, Mackey WC. Children as resources: A cultural analysis. Family Perspective. 1988; 20(4): 251-264.

Des Jariais, DC.; Tross, S.; Friedman, SR. Behavioral change in response to AIDS. In: Wormser, GP.; Stahl, RE.; Battone, EJ., editors. AIDS and other manifestations of HIV infection. NJ: Noyes Publications; 1987. p. 36-47.

Erickson PI, Scrimshaw SM. Contraceptive knowledge and intentions among Latina teenagers experiencing their first birth. Institute for Social Science Research Working Papers, I. 1986:1.

Flora JA, Thoresen CE. Reducing the risk of AIDS in adolescents. American Psychologist. 1988; 43:965-970. [PubMed: 3214009]

Friedman SR, Des Jarlais DC, Sothern JL. AIDS health education for intravenous drug-users. Health Education Quarterly. 1986; 13:383-393. [PubMed: 3781862]

Gary LE, Berry GL. Predicting attitudes toward substance use in a Black community: Implications for prevention. Community Mental Health Journal. 1985; 21:112-118.

Gibbs JT. Psychosocial correlates of sexual attitudes and behaviors in urban early adolescent females: Implications for intervention. Journal of Social Work and Human Sexuality. 1986; 5:81-97.

Guinan ME, Hardy A. Epidemiology of AIDS in women in the United States: 1981 through 1986. Journal of the American Medical Association. 1987; 257:2039-2042.

Koop, CE. The Surgeon General's report on Acquired Immune Deficiency Syndrome. Washington, DC: United States Public Health Service; 1986.

Kristal A. The impact of the Acquired Immunodeficiency Syndrome on patterns of premature death in New York City. Journal of the American Medical Association. 1986; 255:2306-2310. [PubMed: 3959319]

Levanthal H, Cleary PD. The smoking problem: A review of the research and theory in behavioral risk modification. Psychological Bulletin. 1980; 88:370-405. [PubMed: 7422752]

Mantell JE, Schinke SP, Akabas SH. Women and AIDS prevention. Journal of Primary Prevention. in press.

Marin, BV.; Marin, G. Attitudes, expectancies and norms regarding AIDS among Hispanics; Paper presented at the annual meeting of the American Psychological Association; New York, NY. 1987 Aug.

Marmor MJ, Weiss LR, Lyden M, Weiss SH, Saxinger WC, Spira TJ, Feorino PM. Possible female to female transmission of human immunodeficiency virus. Annals of Internal Medicine. 1986; 105:969. [PubMed: 3777723]

Mason JO, Ogden HG, Berreth DA, Martin LY. Interpreting risks to the public. American Journal of Preventive Medicine. 1986; 2:133-139. [PubMed: 3453170]

Mays, VM. AIDS prevention in Black populations: Models and methods of a safer kind. In: Mays, VM.; Albee, GW.; Jones, J.; Schneider, SF., editors. Psychological approaches to primary prevention of acquired immunodeficiency syndrome. Beverly Hills, CA: Sage; in press

Mays VM, Cochran SD. Acquired immunodeficiency syndrome and Black Americans: Special psychosocial issues. Public Health Reports. 1987; 102:224-231. [PubMed: 3104981]

Mays VM, Cochran SD. A survey of knowledge, attitudes and beliefs about AIDS by young Black adults. 1988a Manuscript in preparation.

Mays VM, Cochran SD. Acquired immune deficiency syndrome in women. 1988b Manuscript submitted for publication.

Morgan WM, Curran JW. Acquired immunodeficiency syndrome: Current and future trends. Public Health Reports. 1986; 101:459-465. [PubMed: 3094074]

National Academy of Sciences, Institute of Medicine. Confronting AIDS: Directions for public health care and research. Washington, DC: National Academy Press; 1986.

Nelson MB, Mondanaro J. Health promotion for chemically dependent women. 1981 Unpublished manuscript. 
Pavich EG. A Chicana perspective on Mexican culture and sexuality. Journal of Social Work and Human Sexuality. 1986; 4:47-65.

Poma PA. Pregnancy in Hispanic women. Journal of the National Medical Association. 1987; 79:929_ 935. [PubMed: 3669089]

Ralph N, Spigner C. Contraceptive practices among female heroin addicts. American Journal of Pubic Health. 1986; 76:1016-1017.

Rappaport, J. Community psychology: Values, research and action. New York: Holt, Rinehart, \& Winston; 1977.

Solomon MZ, DeLong W. Recent sexually transmitted disease prevention efforts and their implications for AIDS health education. Health Education Quarterly. 1986; 13:301-316. [PubMed: 3781857]

Spectrum. A close encounter of a safer kind. Washington, DC: Author; 1986.

Street outreach workers. National AIDS Network Multi-Cultural Notes. 1987; 1(6)

Tross, S. Psychosocial and neuropsychological aspects of AIDS; Paper presented at the meeting of the American Psychological Association; New York City. 1987 Aug.

U.S. Bureau of the Census. Characteristics of the population: 1980 census. Washington, DC: U.S. Government Printing Office; 1983.

U.S. Department of Health and Human Services. Health status of the disadvantaged: Chartbook 1986. Washington, DC: U. S. Government Printing Office; 1986. (DHHS Publication No. HRSA HRSP-DV86-2)

Villarosa L, Roberts J. Nobody's safe: AIDS. Essence. 1987; 18:73-74. 118-120.

Warner KE. Television and health education. American Journal of Public Health. 1987; 77:140-142. [PubMed: 3099585]

Weinstein, N. Perceptions of risk; Paper presented at the Centers for Disease Control Conference on Behavioral Aspects of High Risk Sexual Behavior; Atlanta, GA. 1987 Oct.

What you must know about AIDS. Reader's Digest. 1987 Jun.:59-60.

Williams LS. AIDS risk reduction: A community health education intervention for minority high risk group members. Health Education Quarterly. 1986; 13:407-421. [PubMed: 3781863]

Winett, RA. Information and behavior: Systems of influence. Hillsdale, NJ: Erlbaum; 1986.

Women and AIDS. Newsweek. 1986 Jul 14.:60-61.

Worth D, Rodriguez R. Latina women and AIDS. Radical America. 1987; 20:63-67.

Wyatt GE. Jones R. Why we know so little about Afro-American sexuality. Black adult development and aging. in press.

Wyatt GE, Peters SD, Gutherie D. Kinsey revisited Part II: Comparisons of the sexual socializations and sexual behavior of Black women over 33 years. Archives of Sexual Behavior. 1988; 17:289332. [PubMed: 3421826] 


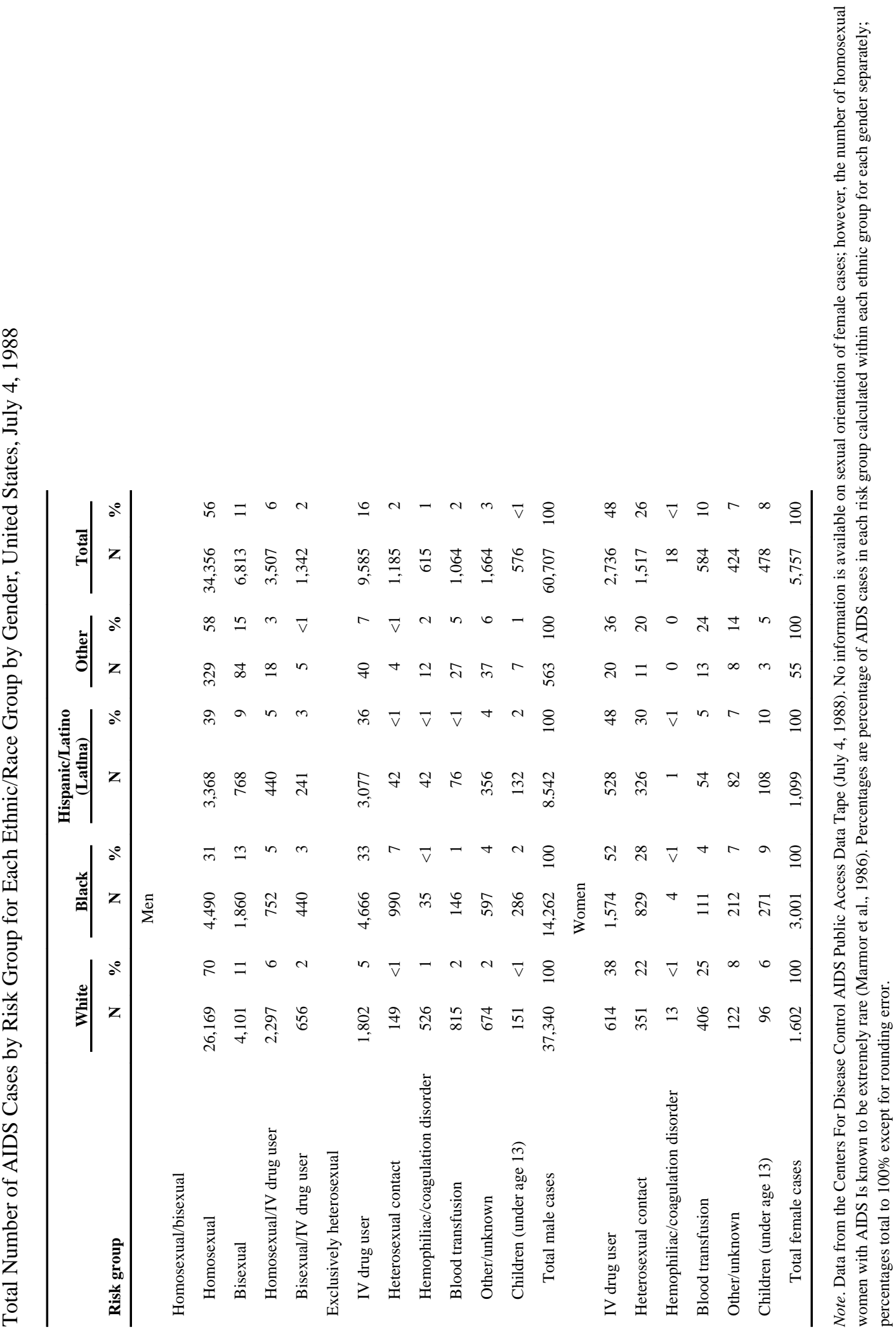

